\title{
Biodiversity and Density of Larvae and Adults of Anopheles Mosquitoes in El Obied City - Sudan
}

\author{
Adam Musa Adam Eissa ${ }^{1, ~ *, ~ M u t m a n ~ A l i ~ A b d l g h d e r ~ K e h a i l ~}{ }^{2}$ \\ ${ }^{1}$ Department of Public Health, Medical Entomology Faculty of Public and Environmental Health, West Kordofan University, Al-nuhud, \\ Sudan \\ ${ }^{2}$ Department of Biotechnology, App. Entomology, Centre of Biosciences and Biotechnology, Faculty of Engineering and Technology, \\ University of Gezira, Wad Madani, Sudan
}

Email address:

domastic28@yahoo.com (A. M. A. Eissa)

${ }^{*}$ Corresponding author

\section{To cite this article:}

Adam Musa Adam Eissa, Mutman Ali Abdlghder Kehail. Biodiversity and Density of Larvae and Adults of Anopheles Mosquitoes in El Obied City - Sudan. International Journal of Health Economics and Policy. Vol. 4, No. 2, 2019, pp. 58-66. doi: 10.11648/j.hep.20190402.14

Received: July 4, 2018; Accepted: August 15, 2018; Published: May 30, 2019

\begin{abstract}
The weather changes especially rainfall affects the distribution and densities of mosquitoes. There are about 380 species of Anopheles, recorded, sixty of them act as vectors of many diseases. This work was carried out to study the biodiversity and density of Anopheles mosquitoes \{adults and larvae\} in El Obied City. A cross-sectional survey of Anopheline mosquito larval habitats was conducted during \{April 2014 - April 2016\}. Larvae were collected by using the standard dipping and netting techniques weekly for the whole year from five selected stations, while adult stages were collected by spray sheet method using Permethrin 25\% E. C. The climatic factors and the malaria cases among the study areas were also recorded. The DNA from the identified adults and larvae was extracted in order to make the molecular confirmation for these species. The results revealed that, all Anopheline mosquito larvae $\{100 \%\}$ which were found and collected from three breeding sites during all seasons were classified as probably Anopheles squamosus. The study also showed that, all $\{100 \%\}$ of adults Anopheline mosquito were classified as most probably A. squamosus and then this result was confirmed by the National Laboratory for Public Health, Medical Entomology Department, Khartoum \{as a first record for this sp.\}. A. squamosus were found only in the shallow pond water habitat in El Obied City. The mean Anopheline density in the study area for larvae was 0.42 per dip while the mean density of adults was 0.55 per room. The high mosquito larval density in El Obied City indicated that, it is at risk of mosquito-borne diseases including malaria. The correlation analysis between mosquito abundance and density to the malaria cases within the selected stations in El Obied City, was positive. The macro and microclimate within which the larvae and the adults $A$. squamosus lived ware also compared to that of other Anopheles species studied before, and new limits were recorded concerning mainly: temperature $\left\{15.5-41.1^{\circ} \mathrm{C}\right\}$, relative humidity $\{16-82 \%\}$ and rainfall $\{6.3-88.2 \mathrm{~mm}\}$ in respect to outdoor and indoor resting mosquitoes specially for adults, and temperature $\left\{24-27^{\circ} \mathrm{C}\right\}, \mathrm{pH}\{6.5-7.2\}$ and salinity $\{1.6-1.9\}$ of larval breeding site waters in addition to the floral types. This study is recommended to be conducted in the other Cities and Sudan.
\end{abstract}

Keywords: Anopheles, squamous, Mosquitoes, El Obied

\section{Introduction}

Mosquitoes are important vectors of several tropical diseases. About one hundred species act as vectors of human diseases. Examples of such disease are malaria, Filariasis, Japanese encephalitis and yellow fever some species were reported to transmit arbovirusis. However, Anopheles spp, beside transmitting malaria, they are capable to transmit Filariasis.
Other biting members of Anopheles spp are nuisance of man [1]. Every 30 seconds a child dies of malaria with the vast majority of deaths occurring in Africa, South of the Sahara. Infection is primarily among pregnant women and children under five years of age, accounting for around $20 \%$ of deaths and $10 \%$ of the continent's overall disease burden [2]. There are at least 300 million acute cases of malaria, each year globally, resulting in a million deaths. Ninety percent of these deaths occur in Africa, mostly in young children. The disease 
has been estimated to cost Africa more than $\$ 12$ billion every year in Gross Domestic Product, even though it could be controlled to a fraction of that amount. Malaria in Africa as a whole accounts for $40 \%$ of public health expenditures, $30-50 \%$ of inpatient admissions, and up to $50 \%$ of outpatients visits in areas with high malaria transmission. Malaria kills more people today than it did 30 years ago. In Sudan Malaria is a disease of considerable magnitude and serious impact, It ranks on the top of the list of diseases with highest rates of morbidity and mortality estimated pointed that each year 7.5 million and 35,000 deaths; this represents $50 \%$ and $70 \%$ of all EMRO cases and deaths. This is in addition to its indirect impact on health services utilization and loss of working days and school absenteeism [3] more details mentioned by [4].

Based on climate models, it is estimated that $75 \%$ of the population of Sudan $\{37$ millions $\}$ are at risk of malaria, while $25 \%$ are at risk of epidemic malaria [5].

Malaria is one of the public health problems in El Obied City. The proportion of malaria cases \{probable and confirmed\} from the total Outpatient attendance are $22.5 \%, 16 \%, 11.5 \%$, $8.5 \%, 8 \%$ in $2009,2010,2011,2012$ and 2013, respectively [6] The general objective was To identify different species and habitats of Anopheles in El Obied City. when the Specific objectives were to record the breeding sites and habitats of Anopheles mosquitoes in El Obied City, To check the distribution of Anopheles mosquitoes within El Obied City and to determine the diversity and density of Anopheles mosquitoes in El Obied City during the study period.

\section{Materials and Methods}

\subsection{Study Area}

A cross-sectional study was conducted during the dry season in randomly selected five stations to reveal the distribution of Anopheles mosquitoes in El Obied City during the period \{April 2014 - April 2016\}. El Obied is a City located in the center of the state of North Kordofan in Sudan. It has an average height of 650 meters above sea level and lies about 588 kilometers south-west of Khartoum, the capital. It is one of the largest cities of Sudan and is renowned as a market for cash crops in Sudan, the largest Bursaha of gum Arabic in the world, and has a historic place in the revolution of Mahdia. It is also an important crossroads, and commercial and agricultural center prominently. Also passes through an oil pipeline extending from south to east to Port Sudan.

\subsection{Measurement of Climate and Microclimate Factors}

El Obied occupies a strategic position in central Sudan between its geographic regions and different climatic and economic: between the desert and semi-desert area, and between savannah zone area dry and wet and between the dry tropics and rainforest areas, western Sudan, south and east. The climatic factors data include temperatures, humidity and rainfall were obtained from El Obeid Airport Map and geographical information $\{2014\}$.

The macro and microclimate within which the larvae and the adults $A$. squamosus lived ware also measured concerning mainly: temperature \{thermometer\}, humidity \{Hygrometer\}and respect to outdoor and indoor resting mosquitoes specially for adults, and temperature \{thermometer\}, pH \{ph-meter\} and salinity \{Measuring Semaphore $\}$ of larval breeding site waters.

\subsection{Collection and Mounting of Mosquito's Samples}

Mosquitoes larvae were collected from different selected breeding sites. Permanent bodies of water such as lakes or stream pools also contained larvae of mosquito species. In addition to that adult stages were collected by rearing larvae in special cages and from different rooms for identification of the species $\}$ and by using spray sheet method to determine Anopheles density during the study period.

A sampling frame was constructed and it consisted of five stations \{which were enumerated according to their geographical locations ffrom north to south, east to west and middle $\}$. The selected stations were randomly picked by using random sampling. Mosquitoes larvae were collected during 12 months from all available breeding sites in the five stations included in the study. From each station, one type of breeding site with positive larvae was photographed \{one from broken pipe or Bricks factory, etc $\}$. The positive Anopheles breeding sites in the five stations were sampled during the all seasons of the year. Larvae \{all instars\} were collected from shallow, bricks factory habitats, jars and broken pipes.

Larval surveys were done weekly using dipping and netting techniques as was recommended by [7] according to the type and size of the breeding place. Identification of larvae was done according to the key of of Common Anopheles larvae in Sudan $\{1960\}$. However, in practice, ten dips were usually taken arbitrarily from each positive site. Larvae were transferred to El Obeid Central laboratory and kept in $70 \%$ alcohol then mounted on slides and identified probably then confirmed from national laboratory for Public Health, Medical Entomology Department \{Khartoum, Sudan - P. O. Box 287\} done according to the key for Identification of [8]. The material which were used for larvae mounting process, include \{pipette, slides, cover glass, pins, D. P. X, filter paper, Petri dish and dissection microscope $\}$.

Adult mosquitoes collected from Five rooms were selected randomly from each selected area by using White Sheets Spray method, techniques as was recommended by [9] according to type and size of the rooms. Identification of adult was done according to the key for Identification of Common Anopheles adult in Sudan $\{1960\}$. However, in practice, adult were usually taken at the morning \{08:30, AM $\}$ from each positive room. Adults were transferred to El Obeid Central laboratory and kept in silica gel then pined and identified probably then confirmed from national laboratory for public health, medical entomology department $\{$ Khartoum, Sudan - P. O. Box 287\} done according to the key for Identification of [8]. The following materials were used: Hudson Pump $\{8 \mathrm{~L}\}$, Permethrin pesticide 25\% E. C, and white sheets and silica gel . 


\subsection{Data Analysis}

The obtained data were first summarized and loaded to Excel program 2007 worksheet. The Pie chart and the descriptive statistics, were run, so as to evaluate the diversity and the density of mosquitoes in El Obeid City.

\section{Results}

\subsection{Mosquito's Diversity and Density}

Results presented in $\{$ Tables $1 \& 2$ and 3 \} during year 2014 which depended on the morphological characteristics presented in Figure $\{1$ and 2$\}$, showed that, the number of Anopheles larvae collected from different types of breeding habitats in El Obeid City during 12 months and indicated that, a total of only 1635 Anopheles mosquito larvae were found and collected from three locations \{Shallow pond of Alrahma west \{north\}, Almodereua \{west\} and Alseka hadied \{middle\} \} during the test period, whereas the other two locations, were not inhibited with mosquito larvae. The collected Anopheles larvae were identified according to their morphological characteristics and the identification proved that $\{1635\} 100 \%$ larvae were identified as probably Anopheles squamosus according to the [10]. and then confirmed from National laboratory for public health, Medical Entomology Department. Other Anopheles spp larvae were not found in all sampled larvae., the mean of Anopheles larvae was 27.25 with standard error SE of 1.168, the standard deviation SD was
12.537, the range \{the difference between maximum and minimum $\}$ was 825 , the minimum $\{\min \}$ number collected was 0 , the maximum $\{\max \}$ number collected was 825 , while the total \{sum\} was 1635 larvae.

It is obvious that, the mean density of Anopheles larvae in shallow habitats \{pond\} were found $\{2.725\}$ per dip $\{1635$ out 50; 5 location and 10 dips, 12 months $\}$ and the mean density of Anopheles larvae in El Obeid City were 0.908 \{1635 out $150 ; 5$ location, 3 habitat and 10 dips $\}$.

As can be seen from \{Table $4 \&$ Table $5 \&$ Table 6$\}$ during year 2015 the descriptive statistics analysis revealed that, the mean Anopheles larvae was 0.520 per dip with standard error SE of 0.171, the standard deviation SD was 4.204, the range \{the difference between maximum and minimum\} was 41 , the minimum $\{\min \}$ number collected was 0 , the maximum $\{\max \}$ number collected was 41 , while the total \{sum $\}$ was 250 larvae. While the collected Anopheles larvae were identified according to their morphological characteristics and the identification proved that $\{250\} 100 \%$ larvae were identified as probably Anopheles squamosus according to the [10]. and then confirmed from National laboratory for public health, Medical Entomology Department. Other Anopheles spp larvae were not found in all sampled larvae.

It is obvious that, the mean density of Anopheles larvae in shallow habitats $\{$ pond $\}$ were found $\{0.416\}$ per dip $\{250$ out $50 ; 5$ location and 10 dips, 12 months $\}$ and the mean density of Anopheles larvae in El Obeid City were 0.138 $\{250$ out $150 ; 5$ location, 3 habitat and 10 dips $\}$.

Table 1. Percentage of larvae Mosquito's diversity which were identified in El Obeid City during 2014.

\begin{tabular}{lllll}
\hline Area & Number of Collected Larvae & \% of An. Squamosus & \% of An. nili \\
\hline Alrahma west & 825 & 100 & 0 & 0 \\
Almodereua & 450 & 100 & 0 & 0 \\
Almatar & 0 & 0 & 0 & 0 \\
Alseka hadied & 360 & 100 & 0 & 0 \\
Arafat & 0 & 0 & 0 & 0 \\
\hline
\end{tabular}

Table 2. Number of Anopheles squamosus larvae and Adults collected from El Obeid City during 2014.

\begin{tabular}{lll}
\hline Number of Area & Number of larvae & Number of Adults \\
\hline Alrahma west & 825 & 680 \\
Almodereua & 450 & 222 \\
Almatar & 0 & 600 \\
Alseka hadied & 360 & 0 \\
Arafat & 0 & 0 \\
Descriptive statistics & & 25 \\
Mean & 27 & 1.528 \\
SE & 1.618 & 11.834 \\
SD & 12.537 & $0-680$ \\
Range & $0-825$ & 0 \\
Min & 0 & 680 \\
Max & 825 & 1502 \\
Sum & 1635 & \\
\hline
\end{tabular}

Table 3. Number and Density of Anopheles squamosus larvae collected from El Obeid City during 2014.

\begin{tabular}{llllll}
\hline \multirow{2}{*}{ Month } & Area & & & & Alseka hadied \\
\cline { 2 - 5 } & Alrahma west & Almodereua & Almatar & 0 & 0 \\
Jan. & 0 & 0 & 0 & 0 & 0 \\
Feb. & 0 & 0 & 0 & 0 & 0 \\
Mar. & 0 & 0 & 0 & 0 & 0 \\
Apr. & 0 & 0 & 0 & 0 & 0 \\
\hline
\end{tabular}




\begin{tabular}{|c|c|c|c|c|c|c|}
\hline \multirow{2}{*}{ Month } & \multicolumn{5}{|l|}{ Area } & \multirow{2}{*}{ Total } \\
\hline & Alrahma west & Almodereua & Almatar & Alseka hadied & Arafat & \\
\hline May. & 0 & 0 & 0 & 0 & 0 & 0 \\
\hline Jun. & 0 & 77 & 0 & 0 & 0 & 77 \\
\hline Jul. & 268 & 92 & 0 & 88 & 0 & 448 \\
\hline Aug. & 292 & 125 & 0 & 104 & 0 & 521 \\
\hline Sep. & 265 & 103 & 0 & 86 & 0 & 454 \\
\hline Oct. & 0 & 53 & 0 & 82 & 0 & 135 \\
\hline Nov. & 0 & 0 & 0 & 0 & 0 & 0 \\
\hline Des. & 0 & 0 & 0 & 0 & 0 & 0 \\
\hline Total & 825 & 450 & 0 & 360 & 0 & 1635 \\
\hline
\end{tabular}

Table 4. Percentage of larvae Mosquito's diversity which were identified in El Obeid City during 2015.

\begin{tabular}{lllll}
\hline Area & Number of Collected Larvae & \%o of An. Squamosus & \% of An. nili & \% of An. Arabiensis \\
\hline Alrahma west & 68 & 100 & 0 & 0 \\
Almodereua & 122 & 100 & 0 & 0 \\
Almatar & 0 & 0 & 0 & 0 \\
Alseka hadied & 60 & 100 & 0 & 0 \\
Arafat & 0 & 0 & 0 & 0 \\
\hline
\end{tabular}

Table 5. Number of Anopheles squamosus larvae and Adults collected from El Obeid City during 2015.

\begin{tabular}{lll}
\hline The Area & Number of larvae & Number of Adults \\
\hline Alrahma west & 68 & 74 \\
Almodereua & 122 & 46 \\
Almatar & 0 & 45 \\
Alseka hadied & 60 & 0 \\
Arafat & 0 & 0 \\
Descriptive statistics & & \\
Mean & 50 & 33 \\
SE & 0.171 & 0.215 \\
SD & 4.204 & 3.729 \\
Range & $0-122$ & $0-74$ \\
Min & 0 & 0 \\
Max & 41 & 38 \\
Sum & 250 & 165 \\
\hline
\end{tabular}

Table 6. Number and Density of Anopheles squamosus larvae collected from El Obeid City during 2015.

\begin{tabular}{|c|c|c|c|c|c|c|}
\hline \multirow{2}{*}{ Month } & \multicolumn{5}{|l|}{ Area } & \multirow{2}{*}{ Total } \\
\hline & Alrahma west & Almodereua & Almatar & Alseka Hadied & Arafat & \\
\hline Jan. & 0 & 0 & 0 & 0 & 0 & 0 \\
\hline Feb. & 0 & 0 & 0 & 0 & 0 & 0 \\
\hline Mar. & 0 & 0 & 0 & 0 & 0 & 0 \\
\hline Apr. & 0 & 0 & 0 & 0 & 0 & 0 \\
\hline May. & 0 & 0 & 0 & 0 & 0 & 0 \\
\hline Jun. & 0 & 7 & 0 & 0 & 0 & 7 \\
\hline Jul. & 18 & 32 & 0 & 13 & 0 & 63 \\
\hline Aug. & 35 & 41 & 0 & 29 & 0 & 105 \\
\hline Sep. & 15 & 23 & 0 & 11 & 0 & 49 \\
\hline Oct. & 0 & 19 & 0 & 7 & 0 & 26 \\
\hline Nov. & 0 & 0 & 0 & 0 & 0 & 0 \\
\hline Des. & 0 & 0 & 0 & 0 & 0 & 0 \\
\hline Total & 68 & 122 & 0 & 60 & 0 & 250 \\
\hline
\end{tabular}

Results explained in that $\{$ Table 7$\} \&\{$ Table 8$\}$, during year 2014, the number of Anopheles adults collected from different types of rooms in El Obeid City and showed that, a total of only 1502 Anopheles mosquito adults were found and collected from three locations $\{5$ rooms per area randomly $\}$; Alrahma west, Almodereua and Almatar during the test period, whereas none was found in the other two locations. The collected Anopheles $\{1502\} 100 \%$ Adults were identified as probably Anopheles squamosus according to their distinguished morphological characteristic features described according to the [10]. And then confirmed by National laboratory for Public Health, Medical Entomology Department. Other Anopheles spp larvae were not found in all sampled Adults.

The descriptive statistics analysis revealed that, the mean of Anopheles adults was 25 with standard error SE of 1.528 , the standard deviation SD was 11.834, the range the difference between maximum and minimum $\}$ was 680 , the minimum $\{\min \}$ number collected was 0 , the maximum $\{\max \}$ number collected was 680 , while the total $\{$ sum\} was 1502 Adults. It is obvious that, the mean density of Anopheles squamosus adults 
in model room was $\{2.50\}$ per room $\{1502$ out $50 ; 5$ locations, 12 months $\}$ and the mean density of Anopheles squamosus adults in El Obeid City were $0.834\{1502$ out $150 ; 5$ locations, 12 month and 3 model rooms $\}$. Results in $\{$ Table 9$\} \&\{$ Table $10\}$, showed the descriptive statistics analysis which revealed that, the mean Anopheles squamosus adults was 0.343 per room with standard error SE of 0.215, the standard deviation SD was 3.729 , the range (the difference between maximum and minimum $\}$ was 38 , the minimum $\{\min \}$ number collected was 0 , the maximum $\{\max \}$ number collected was 38 , while the total $\{\operatorname{sum}\}$ was 165 adults. And when the collected
Anopheles $\{165\} 100 \%$ Adults were identified as probably Anopheles squamosus according to their distinguished morphological characteristic features described according to the [10]. And then confirmed in national laboratory for public Health, Medical Entomology Department. Other Anopheles spp larvae were not found in all sampled Adults.

It is obvious that, the mean density of Anopheles squamosus adults in model room was found $\{0.068\}$ per room $\{165$ out 50 ; 5 locations and 12 months $\}$ and the mean density of Anopheles squamosus adults in El Obeid City was 0.022 \{165 out $150 ; 5$ locations, 12 months and 3 model rooms $\}$.

Table 7. Number and Density of Anopheles squamosus Adults collected from El Obeid City during 2014.

\begin{tabular}{llllll}
\hline \multirow{2}{*}{ Month } & Area & & & \\
& Alrahma west & Almodereua & Almatar & Alseka Hadied & Arafat \\
\hline Jan. & 0 & 0 & 0 & 0 & 0 \\
Feb. & 0 & 0 & 0 & 0 & 0 \\
Mar. & 0 & 0 & 0 & 0 & 0 \\
Apr. & 0 & 0 & 0 & 0 & 0 \\
May. & 0 & 0 & 0 & 0 & 0 \\
Jun. & 0 & 0 & 0 & 0 & 0 \\
Jul. & 242 & 100 & 296 & 0 & 0 \\
Aug. & 438 & 122 & 304 & 0 & 0 \\
Sep. & 0 & 0 & 0 & 0 & 0 \\
Oct. & 0 & 0 & 0 & 0 & 0 \\
Nov. & 0 & 0 & 0 & 0 & 0 \\
Des. & 0 & 0 & 0 & 0 & 0 \\
Total & 680 & 222 & 600 & 0 & 0 \\
\hline
\end{tabular}

Table 8. Percentage of An. Spp. adults in El Obeid City during 2014.

\begin{tabular}{lllll}
\hline Area & Number of Collected Adults & \% of An. Squamosus & $\%$ of An. nili & \% of An. arabiensis \\
\hline Alrahma west & 680 & 100 & 0 & 0 \\
Almodereua & 222 & 100 & 0 & 0 \\
Almatar & 0 & 0 & 0 & 0 \\
Alseka hadied & 600 & 100 & 0 & 0 \\
Arafat & 0 & 0 & 0 \\
\hline
\end{tabular}

Table 9. Percentage of An. Spp. adults in El Obeid City during 2015.

\begin{tabular}{lllll}
\hline Area & Number of Collected Adults & \% of An. Squamosus & \% of An. nili \\
\hline Alrahma west & 74 & 100 & 0 & 0 \\
Almodereua & 46 & 100 & 0 & 0 \\
Almatar & 45 & 100 & 0 & 0 \\
Alseka hadied & 0 & 0 & 0 & 0 \\
Arafat & 0 & 0 & 0 & 0 \\
\hline
\end{tabular}

Table 10. Number of Anopheles squamosus adults collected from El Obeid City during 2015.

\begin{tabular}{llllll}
\hline \multirow{2}{*}{ Month } & Area & & & \\
\cline { 2 - 5 } & Alrahma west & Almodereua & Almatar & Alseka hadied & Arafat \\
\hline Jan. & 0 & 0 & 0 & 0 & 0 \\
Feb. & 0 & 0 & 0 & 0 & 0 \\
Mar. & 0 & 0 & 0 & 0 & 0 \\
Apr. & 0 & 0 & 0 & 0 & 0 \\
May. & 0 & 0 & 0 & 0 & 0 \\
Jun. & 0 & 0 & 0 & 0 & 0 \\
Jul. & 36 & 24 & 21 & 0 & 0 \\
Aug. & 38 & 22 & 24 & 0 & 0 \\
Sep. & 0 & 0 & 0 & 0 & 0 \\
Oct. & 0 & 0 & 0 & 0 & 0 \\
Nov. & 0 & 0 & 0 & 0 & 0 \\
Des. & 0 & 0 & 0 & 0 & 0 \\
Total & 74 & 46 & 45 & 0 & 0 \\
\hline
\end{tabular}




\subsection{The Ecology of the Study Area}

\subsubsection{The Climate Factors}

Results presented in $\{$ Table 11$\}$ showed that, the temperature during 2015 ranged between, $\{15.5$ in December and $41.1^{\circ} \mathrm{C}$ \{in March and May\}\}, while the relative humidity $\mathrm{RH}$ \{Table 12$\}$ ranged between $\{16 \%$ in April $\}$ and $82 \%$ \{in August\}\}, whereas the rainfall amount \{Tables 13 and 14 \} ranged between $\{0$ from November to April\} and $-229.9 \mathrm{~mm}$ \{in August during which the rainy days were 11$\}$, and these values showed the ranges of the climatic factors that Anopheles squamosus can endure.

\subsubsection{The Microclimate Factors}

The temperature $\left\{{ }^{\circ} \mathrm{C}\right\}$ of indoor resting habitat in El Obeid City during 2015 ranged between 23.5 \{in Almodereua area\} and $28^{\circ} \mathrm{C}$ \{in Almatar area\} with a difference of $4.5^{\circ} \mathrm{C}$, while that of outdoor ranged between 36 in Almodereua area\} and $39^{\circ} \mathrm{C}$ \{in Almatar area $\}$ with a difference of $3^{\circ} \mathrm{C}$ Table 15$\}$. The relative humidity $\{\%\}$ of indoor resting habitat in El Obeid City during 2015 ranged between 37\% in Almatar area\} and 82\% \{in Almodereua area $\}$ with a difference of $45 \%$, while that of outdoor ranged between 16\% in Almatar area\} and 40\% \{in Almodereua area \} with a difference of $24 \%$ \{Table 16$\}$. The temperature $\left\{{ }^{\circ} \mathrm{C}\right\}$ in positive larval breeding site waters in El Obeid City during 2015 ranged between 27 (in Almatar area) and $30^{\circ} \mathrm{C}$ in Almodereua area $\}$ with a difference of $3^{\circ} \mathrm{C}$, while that of normal waters ranged between 24 in Almodereua area\} and $28^{\circ} \mathrm{C}$ in Almatar area $\}$ with a difference of $4^{\circ} \mathrm{C}\{$ Table 17$\}$.

The $\mathrm{pH}$ in positive larval breeding site waters in El Obeid City during 2015 ranged between 6.5 in Alrahma west area\} and 7.22 \{in Arafat area\} with a difference of 0.72 , while that of normal waters ranged between 6.55 in Almatar area\} and 7.29 in Almodereua area\} with a difference of 0.74 \{Table 18$\}$. The salinity in positive larval breeding site waters in El Obeid City during 2015 ranged between 1.6 in Alrahma west area\} and 1.9 \{n Almatar area\} with a difference of 0.3 , while that of normal waters ranged between 1.73 \{in Alrahma west area\} and 1.99 in Alseka hadied area\} with a difference of 0.26 Table19\}. The $A n$. $S p$. adults and larvae correlation with Malaria cases was $\{0.64855\}$ while the larvae correlation with Malaria cases was $\{0.92043\}$ in El Obeid City during 2015 \{Table 20\}. The observed values showed the ranges of the microclimatic in which Anopheles squamosus live with in El Obeid City.

Table 11. Temperature Record $\left({ }^{\circ} \mathrm{C}\right)$ in El Obeid City during the year 2015.

\begin{tabular}{llll}
\hline Month & Maximum & Minimum & Mean \\
\hline January & 33.6 & 16.5 & 25.2 \\
February & 36.3 & 18.6 & 27.5 \\
March & 41.1 & 26.8 & 34.0 \\
April & 40.8 & 22.7 & 31.7 \\
May & 41.1 & 25.8 & 36.5 \\
June & 38.0 & 25.3 & 32.3 \\
July & 35.7 & 24.5 & 30.1 \\
August & 32.1 & 22.7 & 27.4 \\
September & 34.8 & 22.6 & 28.6 \\
October & 37.6 & 31.4 & 30.5 \\
November & 36.6 & 18.6 & 28.1 \\
December & 40.5 & 15.5 & 30.5 \\
\hline
\end{tabular}

Table 12. Mean Relative Humidity (\%) and Evaporation in El Obeid City during the year 2015.

\begin{tabular}{lll}
\hline Month & Relative Humidity & Evaporation \\
\hline January & 30 & 7.6 \\
February & 21 & 7.2 \\
March & 18 & 15.6 \\
April & 16 & 6.3 \\
May & 37 & 15.6 \\
June & 56 & 22.2 \\
July & 67 & 23.0 \\
August & 82 & 25.7 \\
September & 72 & 23.4 \\
October & 40 & 13.6 \\
November & 31 & 11.1 \\
December & 36 & 10.1 \\
\hline
\end{tabular}

Table 13. Rainfall (mm) in El Obeid City during the year 2015.

\begin{tabular}{lll}
\hline Month & Total Rain & Rainy Days \\
\hline January & Nil & 0 \\
February & Nil & 0 \\
March & Nil & 0 \\
April & Nil & 0 \\
May & 12.5 & 1 \\
June & 27.6 & 5 \\
July & 88.2 & 10 \\
August & 229.9 & 11 \\
September & 31.6 & 5 \\
October & 4.0 & 2 \\
November & Nil & 0 \\
December & Nil & 0 \\
\hline
\end{tabular}

Table 14. Rains amount (mm) with Rainy days in El Obeid City during the year 2015.

\begin{tabular}{|c|c|c|c|c|}
\hline Month & Date & Amount mm & Total & Rainy days \\
\hline \multirow{2}{*}{ May } & $26 / 5$ & 4.0 & \multirow{4}{*}{6.3} & \multirow{3}{*}{2} \\
\hline & $30 / 5$ & 2.3 & & \\
\hline \multirow{5}{*}{ June } & $5 / 6$ & 9.4 & & \\
\hline & $7 / 6$ & 4.7 & & \multirow{7}{*}{5} \\
\hline & $13 / 6$ & 5.1 & \multirow{6}{*}{27.6} & \\
\hline & $24 / 6$ & 1.7 & & \\
\hline & $23 / 6$ & 6.7 & & \\
\hline \multirow{10}{*}{ July } & $5 / 7$ & 1.7 & & \\
\hline & $12 / 7$ & 1.7 & & \\
\hline & $14 / 7$ & 14.3 & & \\
\hline & $15 / 7$ & 21.0 & \multirow{13}{*}{88.2} & \multirow{13}{*}{10} \\
\hline & $16 / 7$ & 7.6 & & \\
\hline & $17 / 7$ & 6.2 & & \\
\hline & $24 / 7$ & 6.8 & & \\
\hline & $28 / 7$ & 7.3 & & \\
\hline & $29 / 7$ & 0.8 & & \\
\hline & $31 / 7$ & 20.8 & & \\
\hline \multirow{11}{*}{ August } & $5 / 8$ & 0.7 & & \\
\hline & $6 / 8$ & 43.0 & & \\
\hline & $7 / 8$ & 47.0 & & \\
\hline & $8 / 8$ & 3.0 & & \\
\hline & $10 / 8$ & 24.5 & & \\
\hline & $11 / 8$ & 9.7 & & \\
\hline & $15 / 8$ & 1.0 & \multirow{9}{*}{229.9} & \multirow{9}{*}{11} \\
\hline & $16 / 8$ & 7.6 & & \\
\hline & $23 / 8$ & 0.3 & & \\
\hline & $25 / 8$ & 43.7 & & \\
\hline & 29.8 & 49.7 & & \\
\hline \multirow{4}{*}{ September } & $1 / 9$ & 3.0 & & \\
\hline & $5 / 9$ & 2.0 & & \\
\hline & $10 / 9$ & Trace & & \\
\hline & $17 / 9$ & 11.4 & & \\
\hline
\end{tabular}




\begin{tabular}{lllll}
\hline Month & Date & Amount $\mathbf{~ m m}$ & Total & Rainy days \\
\hline \multirow{4}{*}{ October } & $20 / 9$ & 15.2 & 31.6 & 5 \\
& $11 / 10$ & 4.0 & & \\
& $12 / 10$ & Trace & 15.3 & 2 \\
\hline
\end{tabular}

Table 15. Temperature $\left({ }^{\circ} \mathrm{C}\right)$ of indoor and outdoor resting habitat in El Obeid City during 2015.

\begin{tabular}{lll}
\hline Area & Indoor & Outdoor \\
\hline Alrahma west & 24.5 & 37.0 \\
Almodereua & 23.5 & 36.0 \\
Almatar & 28.0 & 39.0 \\
Alseka Hadied & 27.0 & 38.0 \\
Arafat & 26.5 & 37.5 \\
\hline
\end{tabular}

Table 16. Relative Humidity (\%) of indoor and outdoor resting habitat in El Obeid City during 2015.

\begin{tabular}{lll}
\hline Area & Indoor & Outdoor \\
\hline Alrahma west & 72 & 31 \\
Almodereua & 82 & 40 \\
Almatar & 37 & 16 \\
Alseka hadied & 56 & 18 \\
Arafat & 67 & 21 \\
\hline
\end{tabular}

Table 17. Temperature $\left({ }^{\circ} \mathrm{C}\right)$ in positive larval breeding site waters and in normal waters in El Obeid City during 2015.

\begin{tabular}{lll}
\hline Area & $\begin{array}{l}\text { Temperature in positive } \\
\text { larval breeding site waters }\end{array}$ & $\begin{array}{l}\text { Temperature in } \\
\text { normal waters }\end{array}$ \\
\hline Alrahma west & 29.0 & 24.5 \\
Almodereua & 30.0 & 24.0 \\
Almatar & 27.0 & 28.0 \\
Alseka hadied & 28.3 & 27.0 \\
Arafat & 28.5 & 26.5 \\
\hline
\end{tabular}

Table 18. $p H$ in positive larval breeding site waters and in normal waters in El Obeid City during 2015.

\begin{tabular}{lll}
\hline Area & $\begin{array}{l}\mathbf{p H} \text { in positive larval } \\
\text { breeding site waters }\end{array}$ & $\begin{array}{l}\mathbf{p H} \text { in normal } \\
\text { waters }\end{array}$ \\
\hline Alrahma west & 6.50 & 6.86 \\
Almodereua & 6.77 & 7.29 \\
Almatar & 6.61 & 6.55 \\
Alseka hadied & 6.89 & 6.60 \\
Arafat & 7.22 & 7.10 \\
\hline
\end{tabular}

Table 19. Salinity in positive larval breeding site waters and in normal waters in El Obeid City during 2015.

\begin{tabular}{lll}
\hline Area & $\begin{array}{l}\text { Salinity in positive larval } \\
\text { breeding site waters }\end{array}$ & $\begin{array}{l}\text { salinity in normal } \\
\text { waters }\end{array}$ \\
\hline Alrahma west & 1.60 & 1.73 \\
Almodereua & 1.65 & 1.77 \\
Almatar & 1.90 & 1.95 \\
Alseka hadied & 1.70 & 1.99 \\
Arafat & 1.80 & 1.88 \\
\hline
\end{tabular}

Table 20. Number of Anopheles Spp. larvae and adults which correlated with Malaria cases in El Obeid City during 2015.

\begin{tabular}{llll}
\hline Area & $\begin{array}{l}\text { Number of } \\
\text { Collected Larvae }\end{array}$ & $\begin{array}{l}\text { Number of } \\
\text { Collected Adults }\end{array}$ & $\begin{array}{l}\text { Malaria } \\
\text { cases }\end{array}$ \\
\hline Alrahma west & 68 & 74 & 123 \\
Almodereua & 122 & 46 & 130 \\
Almatar & 0 & 45 & 87 \\
Alseka hadied & 60 & 0 & 103 \\
Arafat & 0 & 0 & 67 \\
\hline
\end{tabular}

\begin{tabular}{lll}
\hline An. Ad & Malaria cases & \\
\hline & 0.64855 & $A n$. Ad \\
0.359861 & 0.92043 & An. Lar \\
\hline
\end{tabular}

\section{Number of larvae}

Alrahma west
Almodereua
Almatar
Alseka hadied
Arafat

Figure 1. Pie chart shows number of Anopheles squamosus larvae as collected from Alrahma west \{north\}, Almodereua \{west\} and Alseka hadied $\{$ (middle\} area of (El Obeid City) shallow pond per 12 months 2014.

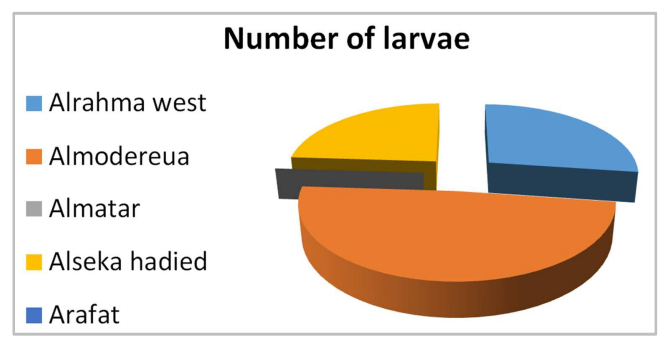

Figure 2. Pie chart shows number of Anopheles squamosus larvae as collected from Alrahma west \{north\}, Almodereua \{west\} and Almatar \{east\} area of \{El Obeid City\} per 12 months 2015.

\section{Discussion}

Sudan is one of the developing countries that falls under the risk of diseases transmitted by Anopheles mosquitoes such as Malaria and other diseases [11]. Malaria contributed considerably to maternal mortality which is $509 / 100,000$ in Sudan [12]. It accounted for $37.2 \%$ of all maternal deaths in Sudan at hospital level. It was also found to be a cause of $18.1 \%$ of low birth weight. Malaria in pregnancy $\{\mathrm{MIP}\}$ is another dilemma, $94 \%$ of clinicians interviewed in a situation analysis of MIP stated that it was a problem [13]. Before any control measures, classification of mosquitoes which transmitted malaria disease is crucial. However, no previous study over the past thirty years was conducted to identify Anopheles species in El Obeid City [6]. Anopheles arabiensis is the principal vector in Sudan. It is the most widespread member of the Anopheles gambiae, abundant throughout most of the Afro- Tropical region, extending northwards along the River Nile to $\approx 20^{\circ} \mathrm{N}$ in Sudan [14]. These findings did not agree with the results of this study, which indicated that An. squamosus is entirely distributed in El Obeid City. There is no other Anopheles species recorded in El Obeid City during the period of this study. It seems that Anopheles mosquito breeds in ponds water. Females and males rested indoor, according to the finding of white sheets method of survey conducted during the study. In Sudan, Anopheles symesi was reported also by [15] in Lake Jur in Faras area \{South Darfur State\}. This finding did not agree with the results obtained in this study. 
Anopheles squamosus was reported also by Musa $\{2013\}$ in shallow pond in the northern west part of $\{\mathrm{El}$ Obied City\}. This finding agreed with the results obtained in this study. Anopheles squamosus larval stages were only collected from Alrahma west, Almodereua and Alseka hadied area because this type of habitats may probably be the best and the available tap water for oviposition of the indoor resting $A n$. squamosus. The $\{1.284\}$ per room and $\{1.570\}$ per dip mean density of An. squamosus was recorded in all locations \{Alrahma west, Almodereua, Almatar and Alseka Hadied and Arafat $\}$ The highest density of An. squamosus indicate that this may be probably were agree with suitable the temperature during the study period which was recorded and ranged between, $\left\{15.5-41.1^{\circ} \mathrm{C}\right\}$ so as the humidity $\{\%\}$ of indoor resting habitat in El Obeid City during the study period which was recorded and ranged between $\{37 \%$ $82 \%\}$ with a difference of $\{45 \%\}$, while that of outdoor recorded and ranged between $\{16 \%-40 \%\}$ with a difference of $\{24 \%\}$ or so as the rainfall rate which were recorded and ranged between $\{0$ and $-229.9 \mathrm{~mm}\}$ and with rainy days which was $\{11\}$, all these according to the climatic factors that Anopheles squamosus can endure. Or may be probably according to the microclimatic factors that Anopheles squamosus live with in El Obeid City which observed, The temperature $\left\{{ }^{\circ} \mathrm{C}\right\}$ in positive larval breeding site waters which ranged between $\left\{27-30^{\circ} \mathrm{C}\right\}$ with a difference of $\left\{3^{\circ} \mathrm{C}\right\}$, while that of normal waters ranged between $\{24-$ $\left.28^{\circ} \mathrm{C}\right\}$ with a difference of $\left\{4^{\circ} \mathrm{C}\right\}$. so as $\mathrm{pH}$ in positive larval breeding site waters ranged between $\{6.5-7.22\}$ with a difference of $\{0.72$,$\} while that of normal waters ranged$ between $\{6.55-7.29\}$ with a difference of $\{0.74\}$, so as the salinity in positive larval breeding site waters ranged between $\{1.6-1.9\}$ with a difference of $\{0.3$,$\} while that of normal$ waters ranged between $\{1.73-1.99\}$ with a difference of (0.26). The study was conducted during all seasons.

Jar, as a habitats recorded high density of anopheline immature instars, this is because most of the people tend to keep water in open jars, therefore amass program of health education messages is urgently needed to raise the awareness of people regarding vector control [4]. These findings did not agree with the results of this study. The present study revealed that is predominant by An. arabiensis followed by An. rufipes and An. pharoensis. These findings [16] These findings did not agree with the results of this study. The highest density of An. squamosus larvae was correlated with Malaria cases which was record $\{0.92043\}$.

\section{Conclusions}

An. squamosus was identified according to MES Key 1960 and confirmed by Medical Entomology Department, the Sudan National laboratory for Public Health.

Biodiversity of larvae and adults of An mosquitoes in El Obeid City, during the study period \{April, 2014 - April, 2016\}. was An. squamosus.

The density of adult stage by using white sheets spray method was 0.916 per room, and this finding indicted that,
An. squamosus resting indoors.

The obtained larval adult stage density indicated that, the inhabitants of area were at risk of mosquito-borne diseases including malaria, which is one of the greatest causes of morbidity and mortality in this area.

\section{Acknowledgements}

I am extremely grateful to. Grateful thanks are due to: Prof. EL Nour Elamin A/Rahman. and Ustaz. Faisal Altaub Hassan. From Academic Health Sciences in Wad Madane town for their advises, Staff faculty of health and environmental Sciences University of Gezira, the staff of the Blue Nile Institute for Communicable Diseases, the staff of the Prof El Gadall Center for training and Malaria Research, Staff faculty of Public and Environmental Health West Kordofan University for their help and facilities Thanks are also due to, Director of Malaria Control Program

\section{References}

[1] Lewis, D. J. $\{1956\}$. The Anopheline Mosquitoes of the Sudan. Bulletin of Entomological Research, 47: 475-494.

[2] WHO $\{1999\}$. Malaria A major Cause of Child Death and Poverty in Africa. International Journal of Epidemiology, 4. P: 231.

[3] El Gaddal, A. A.; Haradi, A. M.; Hassan, F. T. and Hussein, H. $\{1985\}$. Malaria Control in Gezira - Managil Irrigated Scheme of the Sudan. Journal of Tropical Medicine and Hygiene, 88: 153-159.

[4] Gafar, A. A. $\{2009\}$. Distribution and Mapping of Anopheles Mosquitoes in South Darfur State. M.Sc. Thesis. Blue Nile National Institute Communicable Disease. University of Gezira.

[5] RBM, Roll Back Malaria \{2003\}. Progress Report Sudan. April 2004. \{Internet communication, 28 July 2005 at http://www.fmoh.gov.sd/ departments/ malaria / RBM\%20 Sudan\%20.2003.pdf\}.

[6] North Krdofan State Ministry of Health \{2012\}. Malaria, Annual Report. Minisrty of Health, Shikan Locality, North Krdofan State, 2012.

[7] WHO $\{1975\}$. Practical Entomology in Malaria Program Manual $\{$ Vol. 2$\}$; Geneva.

[8] Gilles, M. T. $\{1968\}$. A supplement to the Anopheline of African South of the Sahara \{Afro tropical Region\}. Publication of South Africa Institute for Medical Research, No. 55.Johannesburg.

[9] WHO $\{2002 b\}$. Malaria Entomology and Vector Control; Communicable Diseases Cluster; GENEVA.

[10] Medical Entomology Section $\{1960\}$. Key for Identification of common Anopheles larvae and Adults of Sudan. Medical Entomology Section, National Health Labouratories, P. O. Box 287, Khartoum, Sudan.

[11] WHO \{1982\}. Environmental Management Control Manual; Geneva 22. 
[12] Sudan and UNFPA \{2001\} National Safe Motherhood Survey: Sudan, 1999, Khartoum.

[13] WHO/EMRO \{2001\}. Roll Back Malaria in the Eastern Mediterranean Region; WHOEM/MAL/273/E/G/12.01/3000.

[14] Dukeen, M. Y. H. and Omer, S. M. \{1986\}. Ecology of the Malaria Vector Anopheles arabiensis Patton (Dipterans: Culicidae) by the Nile in Sudan. Bulletin of Entomological Research, 76: 451-467.
[15] Lewis, D. J. $\{1945\}$. Observations on the Distribution and Taxonomy of the Culicidae \{Diptera $\}$ In the Sudan. pp:3, $4,5,6$. University press. pp: $2-46$.

[16] Osman, M. A. $\{2010\}$. Distribution and Mapping of Anopheles Mosquitoes in Senar State. M.Sc. Thesis. Blue Nile National Institute Communicable Disease. University of Gezira. 